\title{
La decisión de matar a Jesús en el evangelio de Juan El martirio de Óscar A. Romero
}

\author{
Manuel de J. Acosta B. \\ San Salvador, EI Salvador.
}

El evangelio de Juan contiene textos en los cuales las autoridades judías toman la decisión de matar a Jesús. Estas decisiones se terminan de materializar en la sentencia de Pilato (Jn 19,16). Este artículo hace un análisis modesto de algunos de estos textos para profundizar en el martirio de Mons. Óscar A. Romero y en su posterior beatificación. Este estudio tiene como trasfondo la afirmación del papa Francisco, en el primer aniversario de su beatificación: "El martirio de Monseñor Romero no fue solo su muerte: inició antes, con los sufrimientos por las persecuciones antes de su muerte y continuó después, porque no bastó que muriera, lo difamaron, calumniaron y enfangaron. Su martirio continuó por manos de sus sacerdotes y del episcopado"'.

\section{El evangelio joánico}

Este evangelio representa una tradición muy peculiar. La figura denominada "el discípulo amado" constituye su origen $(13,23 ; 19,26.35 ; 20,2 ; 21,7.20 .24)$. Este discípulo es un personaje muy cercano a Jesús, pero no figura en el grupo de los doce. Las tradiciones de los sinópticos, quizá conocidas por este evangelio, son transformadas a partir del conocimiento de otras tradiciones jerosolimitanas, samaritanas y griegas, y también a partir de un proceso de reflexión y de una experiencia testimonial. El lector del evangelio se da cuenta de que está ante un nuevo lenguaje.

1. Cfr. www.news.va/es/. "Primer aniversario de la Beatificación de Monseñor Óscar Romero", 23 de mayo de 2016. Consultado el 13 de diciembre de 2017. 
El prólogo (1,1-18) anticipa el desarrollo de la obra, la polémica en la que se verá envuelto Jesús, pero sobre todo presenta conceptos cargados de significado. Cristo es la Palabra de Dios preexistente, el Hijo que desciende del cielo. Este Logos trae la luz y la vida a la humanidad, pero se encuentra con los poderes de las tinieblas. Se trata de la verdad que es y trae Jesús, y de la mentira que se le opone. Los discursos de la primera mitad del evangelio y las controversias con los "judíos" se caracterizan por el uso de este lenguaje, pero también los discursos de despedida de Jesús (13-17), antes de su paso por la pasión. Aun al ser interrogado por Pilato, Jesús se declara rey que ha venido a dar testimonio de la verdad. Esta reflexión sobre Jesús tan elaborada lleva a un conflicto frontal con los "judíos". Jesús les dice "que no conocen a Dios" $(8,19.55 ; 16,3)$. Sus discípulos corren su misma suerte, dado que son expulsados de la sinagoga $(9,22 ; 12,42 ; 16,2)$.

Este evangelio se caracteriza por el dualismo del lenguaje y de los conceptos. A diferencia de los sinópticos, este dualismo no es temporal, sino espacial. Jesús viene "de arriba"; sus adversarios "de abajo". Ellos son "de este mundo", mientras que él no es "de este mundo". Jesús trae la vida, incluso él es la vida; quien se cierra a él, camina en las tinieblas. Jesús trae la verdad, incluso él es la verdad. El antagonista es el "padre de la mentira". El "mundo" puede ser espacio del envío del Hijo, pero también el conjunto de todo lo que se opone a Jesús, a su mensaje y a sus seguidores. En el evangelio de Juan, los representantes del "mundo" que se opone a Jesús son los "judíos", en un sentido específico. En concreto, las autoridades judías de Jerusalén, pero también los representantes de la religión judía, en la medida en que se niegan a creer en Jesús.

La diversidad de grupos judíos que se perciben en los sinópticos se reduce a los fariseos en el evangelio de Juan, lo cual podría explicarse con su origen relativamente tardío. Después de la destrucción de Jerusalén y del templo, en el 70 d. C., los saduceos, los zelotas y los esenios pierden importancia. El grupo de los fariseos, una corriente del rabinismo, es el único que queda. El evangelio de Juan los identifica como los “judíos".

Pero no por eso es un evangelio antijudío. Esa es una impresión engañosa. Ninguno de los evangelios está tan marcado por el judaísmo y sus instituciones, como el cuarto. Esta característica se evidencia en su estructura. En efecto, los viajes de Jesús a las fiestas de peregrinación tienen significado estructural.

La muerte de Jesús, lejos de ser un tema ajeno a este evangelio, constituye su eje vertebrador más profundo. Es decir, si el evangelio de Juan concluyera en 12,50 , su sentido sería muy distinto. Por esto, es importante revisar algunos de

2. Cfr. C. Bernabé, "Las comunidades joánicas: un largo recorrido en dos generaciones", en R. Aguirre (ed.), Así empezó el cristianismo, pp. 318-321 (Estella: Verbo Divino, 2011). 
los pasajes anteriores a la narración de la muerte de Jesús ${ }^{3}$. En especial, aquellos que explicitan la decisión de los "judíos" de asesinarlo. Aquí el estudio de algunos de estos textos.

\section{Estudio de Jn 5,16-18}

Por eso, los judíos perseguían a Jesús, porque hacía estas cosas en sábado. Pero Jesús les replicó: "Mi Padre trabaja hasta ahora y yo también trabajo". Por eso, los judíos trataban con mayor empeño de matarlo, porque no solo quebrantaba el sábado, sino que llamaba a Dios su propio Padre, haciéndose a sí igual a Dios.

Los primeros cuatro capítulos del evangelio de Juan narran la aparición de la Palabra divina (el Logos) en el mundo. Esta Palabra está ahora en la carne de Jesús de Nazaret y quiere suscitar la fe. La humanidad se convierte desde hoy en verdadera sancta sanctorum, hasta ahora presente en el templo jerosolimitano.

El evangelio de Juan está estructurado en círculos concéntricos, que jalonean su lectura literaria. Uno de estos círculos se encuentra después del llamamiento de los discípulos junto al Jordán, en Juan 2-4. A este círculo se le puede llamar "de Caná a Caná". Jesús comienza su actividad en la región de Galilea, pero luego parte hacia Jerusalén a una primera fiesta de pascua $(2,13)$. Allí se da a conocer con palabras y obras, pero al pronunciar su palabra, apenas encuentra fe. Siguen dos viajes, uno a Judea $(3,22-36)$ y otro a Samaria $(4,1-42)$, antes de que Jesús vuelva a Galilea (4,43-45). Cuanto más se aleja de Jerusalén, más fe encuentra. Al final, el funcionario real del segundo signo de Caná representa dicha fe $(4,46-54)$. Así se cierra el primer círculo ${ }^{4}$.

El texto en estudio se encuentra en la sección siguiente, la cual está estructurada por viajes de peregrinación de Jesús durante las fiestas principales de los judíos, antes de la última fiesta de pascua, de 11,55. En Juan 5, Jesús aparece en una fiesta no identificada (v. 1), pero podría ser la fiesta de las semanas. En Juan 7,1-10,21, Jesús se dirige de nuevo a Jerusalén, durante una fiesta de peregrinación. En este caso, la fiesta de las tiendas, mencionada en 7,2. En la fiesta de la dedicación de 10,22, ya está presente en Jerusalén. Estos capítulos se caracterizan por discursos de revelación y controversias con los "judíos". Jesús se esfuerza por suscitar la fe en los israelitas de Jerusalén y de Judea, pero cada vez encuentra más resistencia. Las secciones sobre la fe en Samaria y en Galilea parecen remitir a una época posterior, cuando el mensaje de Jesús fue creído en esas regiones.

3. Cfr. Jn $2,13-22 ; 12,1-8 ; 6,29-59$.

4. Para una comprensión amplia de la estructura del evangelio de Juan, ver J. Beutler, Comentario al evangelio de Juan, pp. $15-19$ (Estella: Verbo Divino, 2016). 
A partir de Juan 6, el contexto es distinto, pues se habla de la Iglesia naciente. La sección pertenece, por un lado, al tema marco de "Jesús y las principales fiestas de los judíos", que desemboca en la última pascual $(11,53)$. Pero, por otro lado, estos capítulos tratan ya de la pasión y del martirio de Jesús y de su resurrección.

\subsection{Contexto literario del texto}

Los puntos de vista narrativos del lenguaje de Juan 5 permiten introducir el contexto del texto. A esto se agregan observaciones sobre el género. La introducción afirma que Jesús subió a Jerusalén a una fiesta de los judíos (v. 1). Luego, los vv. 1-9c narran la curación del paralítico, en el estanque de Betesda. El diálogo de Jesús con el enfermo pertenece al relato de la curación.

El v. 9d menciona que la curación ha sucedido en sábado, lo cual conduce a una serie de diálogos entre los "judíos" de Jerusalén, el aliviado y Jesús (vv. 10-18). El diálogo sube de tono en el v. 18, cuando se dice que los judíos jerosolimitanos tenían mayor empeño en matarlo. Asimismo, expone los motivos para este asesinato anunciado. Uno de esos motivos es curar en sábado, pero esto ya no es tan importante. El otro es una interpretación de las palabras de Jesús en el v. 17 por parte de los judíos. Estos sostienen que lo matarían por llamar a Dios su Padre y por hacerse igual Dios.

El v. 19 introduce discursivamente una larga sección -hasta el final del capítulo, en el v. 47-, que reproduce palabras de Jesús, sin mencionar ya a sus interlocutores. En ella se pueden definir secciones, según los puntos de vista del lenguaje. Los vv. 19-30 están ligados por el paréntesis "el Hijo no puede hacer nada por su cuenta", "por mi cuenta, nada puedo hacer". Esta sección se corresponde con la siguiente, introducida con las palabras "si doy testimonio de mí mismo, mi testimonio no es válido" (v. 31). El tema del testimonio llega hasta el v. 40. Apoyado en las secciones anteriores, se afirma, en el v. 41, "la gloria no la recibo de los hombres". El tema de la gloria determina los vv. 41-44, donde se contrapone la gloria de los hombres con la de Dios. Si alguien busca la gloria de los hombres, no puede entender el testimonio de Dios en las Escrituras de Moisés a favor de Jesús. De ello tratan los versículos conclusivos (45-47).

Los intérpretes no concuerdan sobre el origen de Juan 5. Entre quienes favorecen una tradición o una fuente prejoánica, se pueden reconocer tres modelos: la utilización de una "fuente de los signos", la de una tradición independiente, en particular, en el relato de la curación, y la dependencia de los sinópticos ${ }^{6}$. En la actualidad, es necesario volver a tomar en serio el proceso de redacción del relato

5. Cfr. S. Guijarro, Los cuatro evangelios, pp. 191-202 (Salamanca: Sígueme, 2012).

6. Ibid., pp. 90-102. Puede verse también J. Beutler, Comentario al evangelio de Juan, op. cit., pp. 142-144. 
de la tradición joánica ${ }^{7}$. Esta se puede reconocer en el relato de la curación del paralítico, en Juan 5,2-9c. Quizá Juan combinó el relato de Marcos 3,1-6 ${ }^{8}$ con una tradición jerosolimitana sobre una curación de Jesús en la Puerta de las Ovejas, envuelta en la polémica. Sin embargo, él habría añadido elementos propios. Así, el motivo de la falta de disposición del hombre a aliviarse posiblemente puede entenderse como un ejemplo joánico de "equívoco".

El enfermo solo busca la curación física, pero, para alcanzarla, alguien tiene que bajarlo al agua que se agita. Apartándose del género del relato de milagro, el enfermo no tiene acompañante y el diálogo solo se desarrolla entre él y Jesús. También falta el coro final, en el cual la multitud termina alabando a Dios por el prodigio de poder presenciado. Juan reemplaza el coro por el conflicto del sábado (vv. 9d-15). Esto pone en evidencia la mano de la comunidad, en la elaboración del texto. Además, llama la atención que no es Jesús el primero en quebrantar el sábado, sino el aliviado (v. 8), lo cual pone de manifiesto la situación de las comunidades joánicas, que se refieren constantemente a Jesús para responder a situaciones nuevas. Asimismo, se observa que las comunidades entran en conflicto con el judaísmo de la sinagoga por su interpretación libre de la Torá, desde la memoria de Jesús.

\subsection{La construcción del texto}

Siguiendo el criterio de los personajes, el texto se puede ordenar de la siguiente manera:

A. Jesús y el paralítico. Sanación, en Betesda, en sábado (vv. 1-9): Sanación.

B. Los judíos y el aliviado (vv. 10-13): Acusación.

A'. Jesús y el paralítico (v. 14): Sanación confirmada por Jesús.

$B^{1}$. Los judíos contra el aliviado (v. 15): El aliviado confirma que Jesús lo sanó: Acusación.

C. Los judíos contra Jesús: (vv. 16-18): acusación homicida.

D. Discurso de Jesús (vv. 19-47).

7. Está aceptado que en el relato de los signos, los discursos, los diálogos y la narrativa, el evangelio de Juan desarrolló un proceso de al menos dos generaciones, en la cuales las tradiciones fueron ampliándose y actualizándose, según tiempo y contexto de la comunidad joánica. Ver C. Bernabé, "Las comunidades joánicas: un largo recorrido en dos generaciones", op. cit., pp. 293-340.

8. Se puede ver el estudio de este texto en M. Acosta Bonilla, "Los sumarios sobre la muerte de Jesús en Marcos. Mons. Romero, 'mártir por odio a la fe", Revista Latinoamericana de Teología 95 (2015), 175-199. 
El texto en estudio (C) representa el punto culminante de los literales $A, A^{1} y$ $B, B^{1}$. Es la conclusión de los vv. 1-15, un resumen de la reacción de los judíos al encuentro sanador de Jesús con el paralítico (vv. 1-9), el cual ha tenido lugar en Jerusalén, en Betesda ${ }^{9}$ (v. 1) y en sábado. La reacción consiste en una acusación contra el paralítico sanado: "En sábado, no te está permitido llevar la camilla" (v. 10b). El relato continúa con la confirmación de la sanación, tanto de Jesús ante el aliviado (v. 14) como de este ante las autoridades. El aliviado les proporciona el nombre del autor de dicha sanación.

El punto álgido del relato comienza en el v. 16 y culmina en el v. 18. Este afirma que la sanación llevada a cabo por Jesús se convirtió en acusación y esta, a su vez, en una decisión homicida. Así lo confirma la siguiente sentencia: "por eso, los judíos perseguían a Jesús, porque hacía estas cosas en sábado". El v. 18a recapitula: "los judíos trataban con mayor empeño de matarle". El paso de la acusación a la decisión homicida está descrito con los verbos "perseguir" y "matar".

Este texto introduce el discurso con el que Jesús responde a la acusación homicida de los judíos. El texto es una elaboración de la comunidad joánica, a partir de tradiciones orales sobre Jesús. De esa manera, esta responde a situaciones vitales surgidas en la convivencia con el judaísmo de la sinagoga.

\subsection{Estudio del texto}

Por eso, los judíos perseguían a Jesús, porque hacía estas cosas en sábado. Pero Jesús les replicó: "Mi Padre trabaja hasta ahora y yo también trabajo". Por eso, los judíos trataban con mayor empeño de matarlo, porque no solo quebrantaba el sábado, sino que llamaba a Dios su propio Padre, haciéndose a sí igual a Dios.

El versículo 16 parece ser la conclusión original del relato prejoánico. Los judíos del templo persiguen a Jesús como transgresor del sábado ${ }^{10}$. Esta actitud ya había aparecido en el v. 10, respecto al que había sido curado. El indicativo imperfecto evdi,wkon (perseguían), en su sentido original, indica persecución en sentido religioso". El empleo más antiguo de este verbo en el Nuevo Testamento

9. Cfr. P. Perkins, "Evangelio de Juan", en AA. VV., Nuevo comentario bíblico San Jerónimo (NCBSJ), p. 549 (Estella: Verbo Divino, 2004). El autor presenta un resumen de las principales aportaciones arqueológicas de Betesda.

10. Unos manuscritos antiguos añaden "e intentaban matarlo", pero el texto está respaldado por testimonios textuales egipcios más antiguos. A ello se debe que la afirmación haya sido adelantada en el v. 18. Cfr. E. Nestle y K. Aland, Novum Testamentum Graece, p. 261 (Stuttgart, 1993, edición 27).

11. El Nuevo Testamento conecta el significado del verbo diw, $k w$ con el judaísmo helenístico, en el sentido de persecución religiosa sufrida, en este caso, a causa de Jesús. 
está en las tradiciones de la fuente Q. Ahí, Jesús declara bienaventurados a quienes son perseguidos por causa de la justicia (Mt 5,10). El libro de los Hechos asume una tradición muy reconocida en Israel. Este es un pueblo que persigue a sus profetas (Hch 7,52) ${ }^{12}$.

Esta tradición, que hunde sus raíces en la historia, designa una acción que siempre está sucediendo. En este caso, se trata de un conflicto actual, vivido por la comunidad de Juan. Así, el verbo evoca, en Juan, la persecución sufrida por los profetas de Israel por parte de las autoridades políticas y religiosas del pueblo. Una persecución que también había soportado Jesús por parte de los judíos del templo y que ahora sufre la comunidad de Juan por parte de los judíos de la sinagoga.

Este texto está relacionado temáticamente con Juan 15,20. El pasaje formula el criterio fundamental que debe normar a los discípulos: "El siervo no es más que su señor. Si a mi me han perseguido, también los perseguirán a ustedes". Así, la comunidad de Juan testimonia que Jesús es el profeta perseguido; y anticipa que, así como los "judíos", siendo sus hermanos de religión, lo persiguieron a él, así también y de la misma manera sucederá con sus discípulos.

El fundamento de esta persecución se encuentra en la acusación hecha en Juan 5,10: a Jesús no le está permitido curar en sábado. Pero Jesús contesta esa prohibición con el argumento del v. 17: "El Padre mío hasta ahora trabaja y (también) yo trabajo". Este versículo acentúa el trato personal que Jesús tiene con Dios ("el Padre mío") y el verbo principal: trabajar (evrga,zomai). Este verbo enfatiza que Dios está activo, en el obrar de la naturaleza, pues su obrar no descansa. En este contexto, el pasaje indica que Dios trabaja en la acción permanente de Jesús. Esta es una concepción antropológica propia del judaísmo helenístico.

La tradición sinóptica recoge algunos argumentos utilizados por Jesús para defenderse de la acusación de trabajar en sábado. En efecto, Jesús alega razones de humanidad (Lc 13,15; 14,5). En Juan 7,23, se encuentra un argumento similar. También aduce lo que bien puede caracterizarse como una razón teológica. Jesús argumenta que el Antiguo Testamento permite a los sacerdotes del templo

Este verbo, que en sus orígenes significó pretender alguna cosa con mucho celo, se convirtió, en el ámbito ético y religioso, en acechar a alguien, pero por sus mismos hermanos. Cfr. O. Knoch, "diw, kw", en Diccionario Exegético del Nuevo Testamento, vol. I, p. 1025. En adelante, este diccionario se citará como DENT.

12. Puede verse también Mt 23,34 y Lc 11,49, ambos proceden de la fuente $Q$ y equiparan expresamente los discípulos de Jesús con los profetas. Los logia de Mt 10,23 y Lc 21,12, desarrollos del material de la tradición antigua, pertenecen también a este ciclo de ideas. Apocalipsis 12,13 utiliza la imagen del dragón que persigue a la mujer, que ha dado a luz a su hijo. Asimismo, las cartas originales de Pablo desarrollan la idea de que el discípulo de Jesús es perseguido, como lo fue su Señor (2 Cor 4,$9 ;$ Gal 5,11; 6,12). 
realizar su trabajo, pero él es aún mayor que el templo (Mt 12,5-6). "El Hijo del Hombre es Señor del sábado" (Mt 12,8). El texto que estudiamos aquí es muy parecido.

El v. 17 es una forma teológica de argumentar la actuación de Jesús en sábado. El trasfondo son las relaciones de Dios con el descanso sabático y su actuación en el mundo. Las interpretaciones rabínicas del mandamiento relativo al sábado (Ex 20,11) ${ }^{13}$ advierten que el Señor no dejó de trabajar realmente el sábado, puesto que la providencia está activa todos los días, incluido el sábado. De lo contrario, la naturaleza y la vida habrían dejado de existir, en especial, la vida humana ${ }^{14}$.

Jesús, en Juan 5,17, justifica la curación realizada en sábado recordando a los judíos que ellos mismos, en sus tradiciones, admiten que Dios sigue trabajando en sábado ${ }^{15}$. Dios no descansa. Las implicaciones de este argumento aparecen en el siguiente versículo.

En efecto, el v. 18 retoma la acusación de los judíos (vv. 10.16) y el argumento de Jesús (v. 17), tal como indica la expresión "a causa de esto más..." (dia. tou/to $o u=n$ ma/llon). Los acusadores, basados en estos hechos, concluyen que a Jesús hay que matarlo. Tres causas justifican su asesinato: quebranta el sábado, llama a Dios su propio Padre y se presenta como igual a Dios. La primera causa retoma el v. 5,10, mientras que la segunda y la tercera contienen la interpretación que los acusadores hacen del argumento de Jesús en el v. 17.

La tercera acusación es mencionada de nuevo en Juan 10,33, donde se recoge la reacción de los "judíos" a las obras y las palabras de Jesús. Estos deciden apedrearlo, porque entienden que sus obras y palabras constituyen el intento de quien "siendo hombre, te haces a ti mismo Dios". La acción contra Jesús remite a la condena de los blasfemos, prevista en la Misná (San. 7,4-5) ${ }^{16}$. Pero Jesús desbarata enseguida esta acusación, sin conseguir el efecto deseado. Él se muestra en completa unión con Dios, el Padre: "el Padre está en mí y yo en el Padre" $(10,38)$. Esta acusación da pie para pensar que tanto Jesús como la comunidad de Juan eran vistos como blasfemos, porque anteponían las obras "en nombre de mi Padre" $(10,25)$ al cumplimiento de los preceptos celebrativos de las fiestas judías.

Volviendo a nuestro texto. Los verbos principales de este versículo son buscar y matar. El primero (evzh,toun), que indica una acción benévola (buscar,

13. Cfr. Dt 5,12-15.

14. Cfr. R. Brown, El evangelio según Juan, tomo I, p. 471 (Madrid: Ediciones Cristiandad, 1999). Interpretaciones de 2 Re 5,7; $2 \mathrm{Mac} 7,22-23 ; \mathrm{Gn} 30,22 ; \mathrm{Ez} \mathrm{30,22.}$

15. Cfr. P. Borgen, "The Scriptures and the Words and Works of Jesus", en T. Thatcher, What We Have Heard From the Beginning. The Past, Present, and Future of Johannine Studies, pp. 39-58 (Waco: Baylor University Press, 2007).

16. Cfr. C. del Valle (ed.), La Misná, pp. $737-738$ (Salamanca: Sígueme, 1997). 
escrutar), adquiere aquí un significado hostil, ya que afirma que los judíos podían buscar y destruir una vida, incluso en sábado ${ }^{17}$. Así lo indica el segundo verbo: matar (avpoktei/nai). El verbo designa la conclusión violenta de la vida de Jesús a manos de los judíos y también su mentalidad fundamentalista y agresiva. Los judíos no toleran la actuación de Jesús ${ }^{18}$.

Es la primera vez que este verbo asoma en el evangelio de Juan. A partir de ahora, irá jalonando el resto de la obra. La decisión de los judíos de matar a Jesús aparece en 7,$1 ; 11,53$; y 12,10 . El mismo Jesús es consciente de que lo quieren matar $(7,19 ; 8,37 ; 8,40 ; 1,53 ;$ y 12,10$)$. Asimismo, la comunidad joánica asume firmemente que el judaísmo de la sinagoga asesina creyendo que así da culto a Dios $(16,2)$.

El verbo es clave, porque está dirigido a lectores joánicos, que saben con antelación que Jesús fue perseguido y asesinado por los "judíos". Asimismo, el punto fundamental de la comunidad joánica es la pretensión de Jesús de estar en igualdad con Dios. El tema es prejoánico, puesto que Marcos 2,7 ya había presentado a Jesús acusado de blasfemia, por atribuirse la prerrogativa de pertenecer solo a Dios.

La comunidad joánica asume que Jesús fue perseguido antes de su asesinato, que los "judíos" decidieron matarlo premeditadamente y que, para los verdugos, su crimen estaba suficientemente justificado, tal como lo muestran sus motivaciones, recogidas en el texto. Asimismo, esta comunidad reconoce que Jesús es perseguido después de haber sido asesinado. Los "judíos", sus asesinos, justifican tanto lo que han hecho con él como la persecución y los asesinatos de los miembros de la comunidad del texto, que se autodenomina seguidora de Jesús $^{19}$. La comunidad se siente perseguida y algunos miembros de la comunidad jerosolimitana ya han sido asesinados por los judíos de la sinagoga ${ }^{20}$.

\section{Estudio de Juan 11,53-54}

Por tanto, desde aquel día, resolvieron matarlo. Por eso, él, Jesús, ya no andaba con audacia entre los judíos, sino que se fue de allí a la región cerca del desierto, a una ciudad llamada Efraín y permaneció allí con los discípulos.

17. El mismo significado puede verse en Mc 11,18; 12,12; 14,1. Cfr. M. Acosta Bonilla, "Los sumarios de la muerte de Jesús en Marcos", Revista Latinoamericana de Teología 95 (2015), 179-187.

18. Cfr. H. Frankemölle, "avpokteivnw", en DENT, vol. I, pp. 402-403.

19. $C f r$. Jn 16,2 .

20. Cfr. Hch 4,1-31; 12,1-13. A pesar de ser relatos tardíos, transmiten la tradición de que el judaísmo de la sinagoga de Jerusalén persiguió y asesinó a miembros del movimiento de Jesús. 


\subsection{El contexto literario del texto}

El episodio de la resurrección de Lázaro suscita una reacción doble. Muchos judíos llegan a la fe $(11,45)$, pero algunos acuden a los fariseos, para que procedan contra Jesús $(11,46)$. La sección que sigue describe las consecuencias de la denuncia y la reacción de Jesús ante ella $(11,47-54)$. El capítulo finaliza con una referencia a la fiesta cercana de la pascua y con una mención de los sumos sacerdotes y los fariseos, quienes habían dado órdenes de notificar la ubicación de Jesús para detenerlo (11,55-57).

La sección tiene paralelo con los sinópticos. Se trata de la transmisión de la determinación de las autoridades judías de matar a Jesús, antes de la fiesta de pascua (Mt 26,3-5; Mc 14,1-2; Lc 22,1-2; 19,47). Ciertamente, solo Mateo y Juan conocen una sesión formal del sanedrín con esta finalidad. No es este el sitio para tratarlo, pero se observa que entre la transmisión sinóptica y el texto joánico existe una relación. Al hablar de "sumos sacerdotes y fariseos", Juan tiene contacto con las formulaciones de Mateo (Mt 27,62; 21,45). Cuando se escribe el texto, hacia finales del siglo I, esa composición del sanedrín ya había desaparecido. El único grupo con influencia que quedaba era el de los fariseos, quienes se encuentran detrás del texto.

Desde una perspectiva histórica, es probable que los saduceos, más que cualesquiera de los otros grupos, estuvieran implicados en la determinación de quitar de en medio a Jesús ${ }^{21}$.

El texto forma parte de la sección 11,47-54, que constituye así su contexto. La sección tiene dos partes: (a) los sumos sacerdotes y los fariseos convocaron al sanedrín para deliberar sobre Jesús (vv. 47-52); y (b) la decisión de matar a Jesús (vv. 53-54).

El verbo sina,gw (a reunirse, vv. 47.52), la clave de la primera parte, se encuentra al comienzo y al final. El verbo, colocado al principio del texto, se corresponde con el comentario final del relator, según el cual Jesús no iba a morir por el pueblo, sino "para reunir en uno (sunaga,ghl eivj eln) a los hijos de Dios que estaban dispersos" (v. 52). El verbo enmarca la sección, que así queda definida por una inclusión-oposición. Por una parte, el aparato del poder se reúne, para deliberar sobre el procedimiento a seguir contra Jesús. Y por la otra, él está dispuesto a dar su vida, según el relator, para juntar en uno a los hijos de Dios desperdigados ${ }^{22}$.

21. Cfr. U. C. Von Wahlde, "The Johanine 'Jews'. A Critical Survey", NTS 28 (1982), 33-60. Publicación electrónica, 1 de febrero de 2009. Consultado el 6 de diciembre de 2017.

22. Cfr. R. Brown, El evangelio según Juan, tomo II, op. cit., p. 763. 
La propuesta de definir la sección 11,47-54 por esta "inclusión" puede sorprender, pero se justifica por el uso de estos marcos en otros pasajes del evangelio de Juan. Ya en el prólogo (1,1-18), designa a Jesús como "Dios", en el v. 1 y en el v. $18^{23}$.

La segunda parte, objeto de estudio, pasa del comentario del relator al relato, siguiendo una construcción similar a la del v. 47, "entonces" (ou=n). Según esto, la propuesta de Caifás (v. 49) habría encontrado aprobación. Así, ahora, el sanedrín está decidido a matar a Jesús: y "desde aquel día".

En el v. 54, los datos sobre el lugar reemplazan a los del tiempo. Después de darse a conocer la determinación del sanedrín de matar a Jesús, este ya no se atreve a aparecer en público, entre los judíos o en Judea, sino que se retira al territorio de la ciudad de Efraín, al margen del desierto.

\subsection{La construcción del texto}

A. Los sumos sacerdotes y los fariseos convocaron (sunh,gagon): "¿Qué hacemos?" (v. 47a).

B. Deliberación del sanedrín (vv. 47b-48).

C. Opinión de uno de ellos, Caifás (vv. 49-50).

$\mathrm{A}^{1}$. Comentario del relator: Jesús va a morir para reunir en uno (sunaga, ghl eivj eln) (vv. 51-52).

Conclusión: El sanedrín decide dar muerte a Jesús (vv. 53-54).

El texto está construido por una inclusión y una conclusión. La inclusión está constituida por la palabra convocar o reunir. Mientras los sumos sacerdotes y los fariseos convocan a una reunión para deliberar sobre qué hacer con Jesús (v. 47a), este va a morir para reunir (convocar) en uno a los hijos de Dios dispersos (vv. 51-52). En el centro de la inclusión aparecen dos escenas, que ameritan un comentario.

La primera (vv. 47b-48) está determinada por la pregunta "¿Qué hacemos?". Los sumos sacerdotes y los fariseos, el único poder influyente en la época del evangelista, reúnen al sanedrín para decidir qué hacer con Jesús, para demostrar que, en efecto, ellos detentan el poder. La "fe" en Jesús, la finalidad de este evangelio, es vista como una amenaza. Los sumos sacerdotes y los fariseos expresan un doble temor: los romanos podían llegar y, como grupo dirigente, tomar el "lugar" y el pueblo. Por lo general, el "lugar" se refiere al templo. Pero la palabra to,poj (v. 48) también puede significar la posición social. Sorprende la palabra

23. Puede verse también la sección de 1,19-34, enmarcada por la palabra guía "testimonio", presente en los vv. 19.32.34. La sección "de Caná a Caná" $(2,1-4,54)$, en los vv. 19.46. Cfr. J. Beutler, Comentario al evangelio de Juan, op. cit., p. 295. 
elegida para decir "pueblo": e;qnoj, semejante a la generalmente utilizada para referirse al pueblo étnico: lao,j. Aquella se repite, además, en los vv. 50-52. Por lo visto, en el v. 48, el pueblo (e;qnoj) se entiende más bien como categoría política. Ahora bien, esa expresión no significa que Israel hubiera perdido su dignidad como pueblo. Más bien, es una palabra que enmarca a estos versículos, los cuales se encuentran dentro de la inclusión.

La segunda escena (vv. 49-50) presenta una nueva palabra "uno" (ei-j). Caifás es uno de ellos, es decir, de los sumos sacerdotes y los fariseos. Según su parecer, es mejor que "uno" muera por el pueblo a que todo el pueblo perezca. En el primer caso, el "uno" se opone al grupo de quienes detentan el poder; en el segundo, a todo el pueblo, incluso a la multitud dispersa de los hijos de Dios $(v .52)^{24}$. El sentido de esta relación se aclara en los vv. 51-52. La consideración política realista de Caifás remite a la dimensión salvífica de la muerte de Jesús.

Los vv. 51-52 retoman el tema de la inclusión del v. 47a. Si Caifás es designado "Sumo Sacerdote aquel año"25, significa también que, en ese año, era Sumo Sacerdote. Caifás habla proféticamente, en el mismo sentido del evangelista. No solo anuncia el futuro, sino que también lo interpreta como voluntad salvífica de Dios ${ }^{26}$.

La muerte de Jesús por muchos es un tema que se encuentra en el evangelio de Juan. Precisa la conclusión del discurso de Juan 10,11.17. El Pastor, el Bueno, da su vida por sus ovejas. La idea tiene su trasfondo en la tradición de la cena (Mc 14,24). En Juan, la entrega de Jesús, de su carne, es por la vida del mundo $(\mathrm{Jn} 6,51)^{27}$.

La idea de "reunir" al pueblo (de Dios) disperso se encuentra en las logias de Q (Mt 23,37 par; Lc 13,34): “jJerusalén, Jerusalén, la que asesina a los profetas y apedrea a los que le son enviados! ;Cuántas veces he querido reunir (evpisuna,gw) a tus hijos, como una gallina reúne (evpisuna,gw) a sus pollos bajo las alas, y ustedes no han querido!". Aquí, Jesús refiere a sí lo que, después de los profetas del exilio y de la época posterior al exilio, debía ser la obra escatológica de Dios mismo: reunir a los hijos y a las hijas de la dispersión y llevarlos a Sion ${ }^{28}$.

24. Cfr. R. D. Aus, "The Death of One for All in John 11,45-54 in Light of Judaic Traditions", en Idem, Barabbas and Ester and other studies in the Judaic illumination of earliest Christianity, pp. 29-63 (Atlanta: Scholars Press, 1992).

25. Cfr. Jn 18,13 .

26. Cfr. P. Perkins, "Evangelio de Juan", op. cit., pp. 566-567.

27. Ver también Jn 15,$13 ; 10,13.16 ; 1,9-10 ; 3,16 ; 4,42 ; 6,51$. Resuena un universalismo, propuesto también por Juan. Cfr. R. Brown, El evangelio según Juan, tomo II, op. cit., pp. 768-769.

28. Cfr. Is 11,12 . La obra del ungido será la reunión de los dispersos de Israel. Is 27,12; 40,$11 ; 52,12 ;$ Jr 23,8; Ez 11,17; 28,25; Miq 2,12; Sof 3,19. 
Los textos que hablan de la congregación de los no israelitas en el monte de Sion tienen particular importancia para $\mathrm{Juan}^{29}$. La idea se encuentra tanto en el tercer Isaías como también en Jeremías y en Ezequiel: Dios congregará a los egipcios para llevarlos a Egipto. En estos textos se observa cómo se prepara la afirmación sobre la congregación de los "hijos de Dios dispersos" del v. 52.

Así interpreta la comunidad de Juan la muerte de Jesús. Y para que esta explicación tenga la incidencia esperada, la coloca en boca del verdugo. De esa manera, convierte el conflicto en una oportunidad para resolverlo. La comunidad no esconde la verdad sobre quién mató a Jesús, pero no se queda ahí, sino que procura comprender el significado de su muerte para el verdugo y para los seguidores de la víctima ${ }^{30}$. En esto consiste lo que se llama la astucia política del evangelio de Juan ${ }^{31}$.

La conclusión (vv. 53-54) realiza lo que la inclusión ha planteado ${ }^{32}$. Así terminaba también el año en el cual Jesús, según el ciclo festivo judío, había desarrollado su actuación de pascua a pascua. Ahora se trata de días $(9,4)$. Pronto serán horas $(11,9 ; 19,14)$. Entonces, habrá llegado la "hora de Jesús".

En el v. 54, los datos de lugar reemplazan a los de tiempo. Después de darse a conocer la determinación de asesinar a Jesús, este se retira al territorio de Efraín, en el margen de la ciudad, en el desierto. El centro de la escena del sanedrín lo ocupa el "lugar" (Jerusalén o el templo), mientras que el camino de Jesús va de Jerusalén y de los sitios sagrados a la soledad, al borde del desierto. Ahora permanece solo $(16,32)$. Este movimiento marginal de Jesús es una crítica sutil al modelo dominante, descrito por el sanedrín.

\subsection{El estudio del texto}

Por tanto, desde aquel día, resolvieron matarlo. Por eso, él, Jesús, ya no andaba con audacia entre los judíos, sino que se fue de allí a la región cerca del desierto, a una ciudad llamada Efraín y permaneció allí con los discípulos.

a. "Por tanto, desde aquel día, resolvieron matarlo" (v. 53). La frase es la respuesta a la pregunta "¿qué hacemos?" del v. 47b. Así resolvieron, puesto que la pregunta tiene un sentido deliberativo, con un uso raro de presente. Este sentido actual está relacionado con la expresión "aquel día".

29. Cfr. Jn 11,51.

30. Cfr. J. Dennis, "Conflict and Resolution: John 11,47-52 as the Ironic Fulfillment of the Main Plot-Line of the Gospel of John (John 1,1-12)", SNTUA 29 (2004), 23-39.

31. Cfr. R. Bultmann, The Gospel of John. A Commentary, pp. 411-412 (Westminster: John Knox Press, 1971).

32. La reunión del sanedrín es para decidir la muerte de Jesús, y Jesús, tras su asesinato, reunirá a los hijos e hijas dispersas de Dios. 
La conjugación resolvieron (evbouleu,santo) marca la diferencia literaria respecto a Juan 5,18. El verbo bouleu,omai entraña una decisión planificada. Quiere decir que la resolución adoptada por el sanedrín responde a un plan elaborado. Esta forma de conjugar del verbo solo aparece dos veces en Juan $(11,53 ; 12,10)$, que lo utiliza para señalar el plan de matar a Jesús y a Lázaro ${ }^{33}$. A Jesús no lo mataron por casualidad, sino que su asesinato es la conclusión de un plan orquestado por las autoridades judías.

El versículo resiste la posible interpretación determinista de la muerte de Jesús que hace Caifás, al afirmar que es necesario que uno muera. El texto afirma que el asesinato de Jesús no está en el plan de Dios, sino que fue una decisión deliberada del sanedrín. La comunidad del texto se esfuerza para entender que el plan de Dios continúa, a pesar de la oposición de las autoridades judías. Además, la comunidad entiende que la decisión del sanedrín no ha cambiado después del asesinato de Jesús. Es decir, a Jesús lo siguen matando en los miembros de la comunidad y los autores de esos crímenes son los mismos que se dicen autoridades de la sinagoga.

Según Caifás, es necesario matar a Jesús y cumplir el designio de Dios, y cree que así da culto a Dios (Jn 16,2). Pero para la comunidad de Juan, se trata de una decisión humana, planificada y ejecutada por el sanedrín. Entonces, se ha de cambiar la imagen de Dios. El v. 53 indica que no era necesario asesinar a Jesús. Su asesinato no era un designio de Dios, sino una decisión de la autoridad de entonces. La preocupación de la comunidad, después de la muerte de Jesús, es cómo convertir una decisión y un plan asesino en una oportunidad de reconciliación entre los dispersos.

En este caso, el verbo avpoktei,nw (matar) es la manifestación visible del verbo bouleu,omai (concebir y ejecutar un plan). En la tradición sinóptica, el verbo matar es fruto del corazón humano, es decir, es una decisión interior ${ }^{34}$. Llama la atención que este verbo, en el evangelio de Juan, está presente con más intensidad en la vida pública de Jesús. El relato de la pasión de Juan solo lo utiliza en dos ocasiones. Una en boca de los judíos, que sostienen que a ellos no les es lícito matar a nadie $(18,31)$, y la otra, cuando Jesús afirma que quienes maten a sus discípulos creerán que dan culto a Dios $(16,2)$. Esto indica que la muerte de Jesús es una entrega estrictamente personal ${ }^{35}$ y que el lenguaje asesino y violento no forma parte del habla de Dios.

b. "Por eso, él, Jesús, ya no andaba con audacia entre los judíos, sino que se fue de alli a la región cerca del desierto, a una ciudad llamada Efraín y permaneció allí con los discípulos" (v. 54). Aunque el texto no especifica cómo se hizo

33. Cfr. H. J. Ritz, "bouleu,omai", en DENT, vol. I, pp. 673-676.

34. Cfr. Mt 5,21-22.

35. Cfr. Jn 19,30. 
público el plan de las autoridades judías para matar a Jesús, se da por descontado que ese conocimiento es la razón por la cual Jesús se retira al pueblo de Efraín ${ }^{36}$. Este no responde de la misma manera al plan violento de sus adversarios, sino que busca cómo bajar su perfil. Por eso se aleja (avph/lqen) de la ciudad de Jerusalén y se dirige a las márgenes (eivj th.n $c w$,ran) del desierto. El gesto se encuentra en la tradición sinóptica (Mc 11,19; 14,32).

El hecho de que Jesús ya no ande "con audacia" (parrhsi,al) en Jerusalén, no significa cobardía, sino que ya no gozaba de la libertad que debían tener los ciudadanos $^{37}$. De esta manera, se desvincula del plan concebido por el sanedrín. Ante la actitud homicida de las autoridades, Jesús asume una actitud no violenta. Pero la racionalidad de Jesús no tiene cabida en el plan insensato de los sumos sacerdotes y los fariseos. Sin embargo, su decisión de no andar "con audacia" y de alejarse indica que estos han sido vencidos por él y que, por tanto, lo único que les queda es la fuerza bruta, propia del ignorante. Jesús toma distancia de esa manera de actuar ${ }^{38}$.

El evangelio de Juan dice que Jesús "evitaba andar por Judea" $(7,1)$ y que "se escondió y salió del templo" $(8,59)^{39}$. Las hipótesis interpretativas de esta acción de Jesús son variadas: evita el peligro de muerte con la huida; realmente teme un final violento y protege su vida evadiendo la captura; y huye para poder llevar adelante su proyecto, razón por la cual evita los ataques mortales, que se lo habrían impedido ${ }^{40}$. A pesar de su interés, este no es el momento de discutir estas hipótesis.

Aquí importa que, pese a que las autoridades habían planificado matarlo $(11,53)$ y que habían dado órdenes de que vigilaran sus movimientos $(11,57)$, él no desea morir e hizo lo posible para evitar ser asesinado. Es decir, el asesinato no le parecía necesario para la realización del plan de Dios. Sus seguidores, por otro lado, no habían previsto su muerte violenta. Así, la salida de Jesús a Efraín cuestiona tanto la profecía de Caifás $(11,49-50)$ como la decisión homicida del sanedrín. La muerte violenta no forma parte de la intervención de Dios. Si Jesús trata de huir ante las amenazas, es porque considera que la muerte es un

36. Cfr. P. Perkins, "Evangelio de Juan", op. cit., p. 567.

37. Cfr. H. Balz, "parrhsi,a", en DENT, vol. II, pp. 802-811.

38. Mientras tanto, las autoridades judías no cesarán en el objetivo, tal como lo indica Jn 11,57.

39. Ver también 10,39-40.

40. Cfr. A. Destro y M. Pesce, La muerte de Jesús, investigación de un misterio, pp. 97-135 (Estella: Verbo Divino, 2015). Los autores tratan las previsiones de la muerte de Jesús. Indican que con gran dificultad se puede vislumbrar qué pensaba Jesús acerca de la eventualidad de su muerte o qué peligros y catástrofes se imaginaba. La presentación de los evangelios es tan compleja que solo dejan entrever sus convicciones y las condiciones reales en las cuales se encontraba. 
obstáculo para su proyecto. Por tanto, había que evitarla, en la medida de lo posible, aun cuando contaba con esa posibilidad, puesto que así le había ocurrido al Bautista y porque sus acciones a menudo provocan hostilidad ${ }^{41}$.

La mención que hace el texto de Efraín, un sitio difícil de identificar, dada la variedad de los testimonios manuscritos ${ }^{42}$, enfatiza la presencia de Jesús en lugares periféricos a los centros del poder dominante. El desierto se convierte en el lugar marginal por excelencia para Jesús. Según la tradición sinóptica, ahí se prepara para su vida pública (Mc 1,12-13). Pero, para Juan, el desierto es el lugar donde Jesús se aparta con sus discípulos para prepararse para su muerte a manos de las autoridades judías.

Según el relato, Jesús está acompañado por sus discípulos, lo cual tiene importancia para el lector actual del evangelio. Los discípulos deben estar con él, no solo para mostrarle su solidaridad, sino también para ir con él a su escuela de la periferia, hasta el final. Una escuela donde se capta el sentido profundo de la vida y la muerte de Jesús. En el relato, el lector-discípulo de Jesús aprende a configurar su identidad según su ejemplo. El modelo está en la periferia, no en el centro del poder.

Simultáneamente, los discípulos, según el texto, conforman el núcleo del pueblo (de Dios) renovado. Si él, al morir por los muchos, va a reunir al pueblo (de Dios) disperso, el movimiento de reunión comenzará con los discípulos, en las periferias, y será proseguido por ellos. Los discípulos constituyen el germen de un modelo social alternativo al centro dominante. El punto de partida de la alternativa se encuentra en la periferia.

Llegados hasta aquí en el análisis de los textos, conviene ahora hacer algunas consideraciones, en función del objeto de este estudio. Los textos abordados forman parte de una temática más amplia del evangelio de Juan, a saber, la muerte violenta de Jesús y sus repercusiones en la comunidad joánica. Los relatos analizados afirman la responsabilidad directa de los líderes religiosos de los "judíos" en el asesinato de Jesús ${ }^{43}$. Juan 5,16-18 afirma que los "judíos", sus autoridades religiosas, persiguen a Jesús hasta empeñarse en asesinarlo. Las razones literarias son haber curado en sábado y hacerse igual a Dios. El evangelio de Juan introduce desde el comienzo la determinación explícita de esas

41. Cfr. J. D. Dunn, Jesús recordado. El cristianismo en sus comienzos, tomo I, pp. 898-899 (Estella: Verbo Divino, 2009). Según el autor, lo más probable es que Jesús esperase correr la suerte de los profetas, el martirio en Jerusalén como consecuencia de su actividad. Jesús debía tener muy presente lo sucedido a su mentor, Juan el Bautista. Si bien este había sufrido a manos de Antipas, difícilmente podía Jesús pensar que las cosas iban a ser diferentes en Judea.

42. Cfr. R. Brown, El evangelio según Juan, tomo II, op. cit., p. 766.

43. Cfr. A. Destro y M. Pesce, La muerte de Jesús, op. cit., pp. 155-160. 
autoridades de matar a Jesús ${ }^{44}$. El relato es el culmen del rechazo de los suyos a Jesús, planteado en el prólogo del evangelio (Jn 1,11). Los "suyos" constituyen, en el contexto de la comunidad de Juan, sus hermanos de religión judía, los de su patria y los de su raza.

El texto presenta a los “judíos”, sus autoridades religiosas, como los perseguidores y homicidas tanto de Jesús como de la comunidad que se encuentra detrás del relato. En el contexto histórico de la comunidad joánica, las autoridades son los fariseos de la sinagoga, posteriores al año 70, mientras que, en el caso de Jesús, son lo saduceos del templo de Jerusalén. Sin embargo, es evidente que la religión judía, sus autoridades, persigue y mata a sus propios hermanos de religión. Jesús, un hermano de religión, plantea la renovación religiosa judía, en especial, la imagen de Dios del judaísmo del siglo $\mathrm{I}$.

Juan 11,53-54 se encuentra al final de la vida pública de Jesús. El texto constituye el culmen literario del empeño de las autoridades judías para matar a Jesús, porque se hacía igual a Dios y porque curaba en sábado. El relato cuenta cómo el sanedrín planifica el final violento de Jesús. Todas las autoridades son religiosas. Asimismo, expone la paradoja de que mientras esas autoridades se reúnen para planificar la muerte de Jesús, la comunidad joánica interpreta que su muerte violenta significará la reunificación de los hijos de Dios dispersos. La astucia política de la comunidad consiste en que pone esa interpretación en boca de Caifás, el Sumo Sacerdote, uno de los verdugos de Jesús. De esta manera, el texto se distancia de la interpretación determinista, al mismo tiempo que descubre en la muerte de Jesús una oportunidad para la reconciliación de los verdugos ("los hijos de Dios dispersos") con la comunidad de Juan, que se considera víctima de esa injusticia.

Jesús, al conocer la existencia del plan homicida, se marcha con sus discípulos al desierto. Se trata de un movimiento geográfico de carácter marginal, que indica, por un lado, el distanciamiento de Jesús de la irracionalidad homicida de las autoridades y, por el otro lado, el temor a finalizar su vida de forma violenta. Asimismo, Jesús indica que este final no es voluntad de Dios, sino decisión de las autoridades religiosas. De esa manera, visibiliza su ignorancia religiosa y su derrota, al no ser capaces de renunciar a la violencia.

44. Decir que Jesús murió a causa de la hostilidad manifiesta contra él desde el inicio por ciertos ambientes judíos, hacía recaer sobre estas categorías, y no sobre los romanos, la responsabilidad, al menos moral, de la ejecución. Los motivos por los cuales habría sido perseguido por las autoridades judías serían, por consiguiente, de carácter doctrinal y por la interpretación de la Ley. Y este aspecto era fundamental, cuando sus seguidores se esforzaban por establecer la diferencia respecto a otros grupos. 


\section{Conclusión: los miedos de Mons. Romero y su triple martirio}

Los miedos humanos de Jesús ante su muerte violenta se historizan en la vida de Mons. Romero. En su último retiro espiritual, un mes antes de su asesinato, expresó los siguientes temores: "Temo las influencias ideológica y política [...] que mis consejeros más íntimos crean que ya no influyen en mí [...] siento miedo a la violencia en mi persona [...] por la debilidad de mi carne"45. En algunas ocasiones, estos miedos estaban acompañados de escrúpulos espirituales. "Vino el P. Azcue [...] me orientó comentando que puede haber inclinaciones de escrúpulos en cuanto a las confesiones y que lo principal eran las disposiciones interiores ${ }^{206}$.

El temor de Mons. Romero a una muerte violenta es importante. Al igual que Jesús de Nazaret, no acepta que este fuera el final necesario para que la paz con justicia llegara a El Salvador. Sin embargo, asume el riesgo, en medio de la debilidad humana ${ }^{47}$.

Mi otro temor es acerca de los riesgos de mi vida. Me cuesta aceptar una muerte violenta, que en estas circunstancias es muy posible [...] el padre [Azcue] me dio ánimo diciéndome que mi disposición debía ser dar mi vida por Dios, cualquiera que sea el fin de mi vida. Las circunstancias se vivirán con la gracia de Dios [...] pero que más valioso que el momento de morir, es entregarle toda la vida y vivir para él18.

En el caso de Mons. Romero, los autores de la violencia contra él fueron fundamentalmente dos: el gobierno militar de turno y los obispos, los presbíteros y los movimientos eclesiales que rechazaban la renovación de la Iglesia, según el evangelio de Jesús, que él historizó, inspirado en el concilio Vaticano II $^{49}$.

Mons. Romero ha sido llevado al martirio tres veces. Según el papa Francisco, "su martirio le siguió lapidando con la piedra más dura que existe en el mundo: la lengua" 50 . La afirmación del papa tiene trasfondo bíblico jesuánico. La religión israelita, al institucionalizarse en la monarquía y en el sumo sacerdocio levita, se caracterizó, entre otras cosas, por perseguir y matar a sus profetas. Jesús y su movimiento originario fueron víctimas de esta persecución. La gran Iglesia, al

45. Cfr. Ó. A. Romero, Cartas pastorales, discursos y otros escritos, tomo VII, p. 539 (San Salvador: UCA Editores, 2017).

46. Ibid., p. 543.

47. La tradición paulina lo denominó "la fuerza de la debilidad" (2 Cor 12,9-12).

48. Cfr. Ó. A. Romero, Cartas pastorales, tomo VII, op. cit., p. 543.

49. A. M. Ventura, "Monseñor Vincenzo Paglia: 'Romero es el primer mártir de la Iglesia del concilio Vaticano II"', Radio Nacional de El Salvador, 12 de marzo de 2015. Disponible en http:/www.radionacional.gob.sv/2015/03/12/monsenor-vincenzopaglia-romero-es-el-primer-martir-de-la-iglesia-del-concilio-vaticano-segundo/.

50. Cfr. "Primer aniversario de la beatificación de Monseñor Óscar Romero", op. cit. 
pretender institucionalizar el proyecto de Jesús, dejó de ser perseguida y pasó a ser perseguidora, con algunas excepciones.

Esto se percibe en el martirio de Mons. Romero, un mártir in odium fidei $i^{55}$. En él, se repite casi literalmente el proceso contra Jesús, dado que sus hermanos de fe católica avalan y justifican su muerte. Aunque la orden de matarlo la dio un miembro del gobierno de entonces ${ }^{52}$. Testimonios orales recientes aseguran que varios miembros de la prelatura del Opus Dei mandaron a ofrecer misas y rosarios para dar gracias a Dios porque lo habían matado. Varios obispos, incluidos algunos de los actuales, reprimieron y persiguieron a quienes querían mantener viva su memoria. Así, Mons. Romero es mártir antes, en y después de su asesinato.

Esta es una advertencia para la conversión de la Iglesia actual. La marginación y el desconocimiento al que la alta jerarquía eclesiástica sometió a Mons. Romero hasta que el papa Francisco lo reconoció, es una llamada para revisar el modelo actual de Iglesia. La conversión consiste en volver a Jesús. Es necesario admitir con humildad que seguimos matando a Jesús, o bien lo encapsulamos en el sagrario. Esto solo se puede evitar poniendo la institución eclesiástica al servicio del proyecto de Jesús, para lo cual es necesario reconocer prácticas que, a veces, pueden ser política y religiosamente incorrectas. Los fundamentalismos y lo extremadamente canónico alejan a la Iglesia de la profecía de Jesús.

En cambio, Mons. Romero fue un profeta. En su contexto, planteó si era lícito invocar la objeción de conciencia y llamar a los soldados a que desobedecieran las órdenes de sus superiores. Así, los invitó a escuchar la voz de su conciencia y la ley de Dios antes que acatar las órdenes injustas de sus superiores. Asimismo, relativizó el precepto de la misa dominical y llamó a participar en una misa única para protestar contra el asesinato del padre Rutilio Grande.

Jesús y Mons. Romero son profetas débiles. Los textos del evangelio de Juan, en especial los relacionados con su vida pública, presentan a Jesús huyendo del peligro. Juan 11,54 afirma que no andaba "con audacia", lo cual señala su debilidad humana. Jesús no fue un ser superhumano. Al contrario, invita a contemplar al Dios débil. De la misma manera, Mons. Romero experimentó el miedo y sufrió de escrúpulos. No fue un héroe, ni quiso serlo. En la actualidad, reclamaría honradez y ecuanimidad en el culto que la Iglesia le tributa. El honor que se le rinde, con sus dificultades, siempre ha sido más sincero en el entorno

51. Cfr. M. Acosta Bonilla, "Los sumarios sobre la muerte de Jesús en Marcos", op. cit., pp. 195-199.

52. Según el informe de la Comisión de la Verdad, la orden de asesinar a Mons. Romero la dio el mayor Roberto D'Aubuisson. Cfr. http://www.unesco.org.uy. Organización de las Naciones Unidas, Informe de la Comisión de la Verdad para El Salvador, 1992-1993, versión digital, 137. Consultado el 15 de diciembre de 2017. 
extraeclesial. Mons. Romero es santo en el corazón de los pobres antes que en los expedientes canónicos de la Iglesia jerárquica.

El gran reto que plantea el triple martirio de Mons. Romero es la reconciliación. Así como la comunidad joánica puso en boca del verdugo Caifás que la muerte violenta de Jesús reuniría a los hijos dispersos de Dios, la Iglesia salvadoreña necesita paz interna. Mons. Romero quiso que su muerte contribuyera a la reconciliación eclesial.

Debemos aceptar que con Mons. Romero nos equivocamos, de la misma manera en que la religión judía se equivocó con Jesús. Esa equivocación evidencia la necesidad de una sanación interna. No basta con dar culto a Mons. Romero, cuando las divisiones y las desconfianzas entre grupos eclesiales, que se remonta a su época, todavía persisten. La Conferencia Episcopal de El Salvador debe iluminar a las distintas tendencias eclesiales desde el modelo de Iglesia propuesto por Mons. Romero y elaborar un programa de formación presbiteral en correspondencia con él. Es necesario recuperar su visión sobre el papel de la Iglesia en medio de las organizaciones populares de su época. Se trata de un modelo muy similar a "la Iglesia en salida y accidentada", propuesta por el papa Francisco. 